\title{
Perbandingan Komunitas Plankton di Sungai Cisadane Kota Tangerang pada Tata Guna Lahan yang berbeda
}

\author{
Desy Rosarina*1 ${ }^{1}$, Ellysa Kusuma Laksanawati ${ }^{2}$, Dewi Rosanti ${ }^{3}$ \\ *e-mail: derosa.heryansyah@gmail.com \\ ${ }^{1,2}$ Universitas Muhammadiyah Tangerang \\ ${ }^{3}$ Universitas PGRI Palembang
}

\begin{abstract}
Research that examines the plankton community structure on different land uses in the Cisadane River in Tangerang City has been carried out from April to June 2019. This study uses a survey method. Determination of the location is done by purposive sampling, adjusted to land use, namely fishing grounds, residential areas and factory / industrial areas. Sampling points for fisheries and residential areas are in Karawaci Hilir (station 1), Babakan (station 2) and Sukajadi (station 3). The sampling points of the factory area are around the tofu mill (station 1), the paper mill (station 2) and the palm oil mill (station 3) all in Karawaci Hilir. Data analysis in the Biology laboratory, Faculty of Mathematics and Natural Sciences, PGRI University, Palembang. The plankton community structure on the Cisadane river on different land uses consists of 22 phytoplankton species and 8 zooplankton species. The highest abundance of phytoplankton is owned by Synedra ulna and the highest abundance of zooplankton is owned by Cyclops scutifer. Plankton diversity in three land uses can be categorized as moderate, with a diversity index value ranging from 1.27-2.82.
\end{abstract}

Keywords: water quality, pollution, Cisadane river

\begin{abstract}
ABSTRAK
Penelitian yang mengkaji struktur komunitas plankton pada tata guna lahan yang berbeda di Sungai Cisadane Kota Tangerang telah dilakukan dari bulan April hingga Juni 2019. Penelitian ini menggunakan metode survey. Penentuan lokasi dilakukan secara purposive sampling, disesuaikan dengan tata guna lahan yaitu kawasan penangkapan ikan, kawasan pemukiman dan kawasan pabrik/industri. Titik pengambilan sampel untuk area perikanan dan area perumahan berada di Karawaci Hilir (stasiun 1), Babakan (stasiun 2) dan Sukajadi (stasiun 3). Titik pengambilan sampel area pabrik adalah di sekitar pabrik tahu (stasiun 1), pabrik kertas (stasiun 2) dan pabrik minyak kelapa sawit (stasiun 3) semuanya di Karawaci Hilir. Analisis data di laboratorium Biologi Fakultas MIPA Universitas PGRI Palembang. Struktur komunitas plankton di sungai Cisadane pada tata guna lahan yang berbeda terdiri dari 22 species fitoplankton dan 8 species zooplankton. Kelimpahan fitoplankton tertinggi dimiliki oleh Synedra ulna dan kelimpahan zooplankton tertinggi dimiliki Cyclops scutifer. Keanekaragaman plankton di tiga tata guna lahan dapat dikategorikan sedang, dengan nilai indeks keanekaragaman berkisar 1,27-2,82.
\end{abstract}

Kata Kunci: kualitas air, pencemaran, sungai Cisadane

\section{PENDAHULUAN}

Salah satu masalah terpenting dalam suatu badan perairan adalah
pencemaran.Pencemaran air menurut Peraturan Pemerintah RI No. 82 tahun 
2001 adalah masuknya atau dimasukkannya mahluk hidup, zat, energi, dan atau komponen lainnya ke dalam air dan atau berubahnya tatanan air oleh kegiatan manusia, sehingga kualitas air turun sampai ke tingkat tertentu yang menyebabkan air tidak dapat berfungsi lagi sesuai peruntukkannya (Agustiningsih et al., 2012).

Kualitas air dapat diukur berdasarkan sifat fisika, kimia dan biologinya. Sifat biologi yang menjadi indikator kesuburan suatu badan perairan adalah kelimpahan plankton.Kelimpahan plankton dapat diukur di badan perairan seperti sungai.Daerah aliran sungai biasanya sebagai tempat pembuangan limbah domestik dan pabrik.

Kawasan sungai yang memiliki karakteristik demikian diantaranya adalah sungai Musi dan sungai Cisadane. Kedua sungai ini sama-sama merupakan daerah tangkapan ikan, pabrik, taman wisata dan perumahan, dimana keduanya menjadi tempat pembuangan limbah.

Salah satu perairan mengalir adalah sungai Musi dan sungai Cisadane. Sungai Musi merupakan sungai yang menjadi muara puluhan sungai besar dan kecil lainnya, baik di Bengkulu maupun Sumatera Selatan. Sungai ini memiliki panjang sekitar 720 kilo meter dan melintasi kota Palembang. Berbagai aktivitas Industri seperti pertambangan, perkebunan, pertanian, aktivitas rumah tangga, maupun aktivitas alami yang masuk ke perairan sungai ini berdampak terhadap biota perairan dan kesehatan. Aktivitas tersebut juga mengakibatkan terpaparnya logam berat seperti merkuri ke dalam badan sungai. Kegiatan industri, pertanian, dan aktivitas manusia menjadi penyebab meningkatnya jumlah buangan atau polutan di perairan dan merusak lingkungan. Masyarakat sepanjang aliran Sungai Musi memanfaatkan air sungai ini untuk memenuhi kebutuhan hidup,mengairi lahan, usaha perikanan, dan transportasi.
Sungai Cisadane adalah salah satu sungai besar di Tatar Pasundan, Pulau Jawa, yang bermuara ke Laut Jawa. Hulu sungai ini berada di lereng Gunung Pangrango, dengan beberapa anak sungai yang berawal di G. Salak, melintas di sisi barat Kabupaten Bogor, terus ke arah Kabupaten Tangerang dan bermuara di sekitar Tanjung Burung. Beberapa tahun terakhir kawasan sungai Musi dan Cisadane berhubungan langsung dengan aktifitas publik, kegiatan beberapa industri dan pemukiman, kantor, restoran dan cafe. Selain itu, Pemkot Tangerang dan Palembang telah melakukan penataan sungai berupa area publik. Kini, masyarakat Kota Palembang dan Tangerang bisa menikmati keindahan sungai Musi dan Cisadane sambil bermain di taman yang aman dan cukup nyaman untuk dijadikan tempat nongkrong. Ada bangku taman, dan ada pula beberapa permainan untuk anakanak (Rosarina dan Laksanawati, 2018.b).

Seperti lazimnya sungai di Indonesia, sungai Musi dan Cisadane telah menjadi penunjang pembangunan ekonomi Kota Palembang dan Tangerang. Kedua sungai ini sejak lama berfungsi untuk pengairan lahan pertanian, pemenuhan kebutuhan bagi industri, dan untuk memenuhi kebutuhan air bersih atau minum bagi rumah tangga.

Sungai Cisadane dan sungai Musi juga menjadi jalur transportasi dengan perahu kecil untuk menyebrangkan warga dari tepian yang satu ke tepian yang lain. Para nelayan juga bisa mengambil kekayaan sungai untuk mencari ikan.Kesemua aktivitas tersebut mempengaruhi kualitas air dan mempunyai petensi mencemari perairan di sungai Cisadane, yang berdampak pada menurunnya kualitas air (Rosarina dan Rosanti, 2018; Rosarina dan Laksanawati, 2018.a). Menurut Tajangenyasha dan Dzinomwa dalam Agustiningsih et al. (2012), perubahan 
kondisi kualitas air sungai merupakan dampak dari buangan kegiatan industri dan pemukiman di sekitar daerah aliran sungai.

Pengukuran kualitas air bertujuanuntuk mengetahui kelayakan dari air tersebut. Dalam penelitian ini, pengukuran kualitas air dilakukan di beberapa titik di sepanjang sungai Musi dan Cisadane, dengan menggunakan metode survey, dan pengambilan data dilakukan secara purposive sampling, yaitu pengambilan sampel dilakukan dengan memperhatikan berbagai pertimbangan kondisi serta keadaan daerah pengamatan.

Dari uraian tersebut kajian kualitas perairan dapat ditinjau dari sifat fisika, kimia dan biologi. Sifat biologi yang dapat menjadi indikator tingkat pencemaran adalah komunitas plankton dan kandungan bakteri Escherichia coli.Perlu dikaji komunitas plankton pada tata guna lahan yang berbeda di Sungai Cisadane, sebagai sumber aktivitas manusia diantaranya pemukiman dan industri dan kegiatan nelayan.

\section{BAHAN DAN METODE}

Penelitian dilakukan pada bulan Juni sampai Juli 2019 di tiga kawasan tata guna lahan sepanjang aliran Sungai Cisadane Kota Tangerang, dengan metode survey. Sampling data dilakukan secara purpossive.Metode pengambilan sampel mengacu pada penelitian Rosarina dan Rosanti (2018).

$$
\text { Sampel plankton diambil }
$$
menggunakan ember bervolume 5literdengan 8 kali ulangan, lalu disaring menggunakan plankton net 25 ukuran jaring $60 \mu \mathrm{m}$.
Sampel air 1 diberi larutan lugol sebanyak 3 tetes. Setiap sampel dituliskan data lokasi dan tanggal pengambilan sampel.

Plankton diamati di bawah mikroskop dan diidentifikasi menurut Mizuno (1979) serta Kusmeri dan Rosanti (2015). Analisis data dilakukan di laboratorium Biologi Fakultas MIPA Universitas PGRI Palembang.

\section{Analisis Data}

Kelimpahan plankton

Perhitungan individu plankton dilakukan dengan Sedgwick RafterCountingyaitu secara Strip Counting. Kelimpahan individu zooplankton dengan rumus menurut Edmonson (1971) dalam Dwirastina et al. (2013) serta Wahyuni dan Rosanti (2016)yaitu :

$$
\mathrm{N}=(\text { ns x va) } /(\text { vs x vc) }
$$

\section{Dimana :}

$\mathrm{N}$ : Jumlah individu plankton per liter air contoh

ns : Jumlah individu plankton pada Sedwick Rafter)

va : Volume air terkonsentrasi dalam botol vial $(25 \mathrm{ml})$

vs : Volume air dalam peparat Sedwick Rafter $(1 \mathrm{ml})$

vc : Volume air contoh yang disaring (40 liter).

\section{HASIL DAN PEMBAHASAN}

\section{Komposisi dan Kelimpahan Plankton}

Plankton yang ditemukan di Sungai Cisadane terdiri dari 22 species fitoplankton dan 8 species zooplankton. Kelimpahan masing-masing species disajikan pada tabel 1 berikut ini. 
Tabel 1. Kelimpahan Plankton di Sungai Cisadane Kota Tangerang

\begin{tabular}{|c|c|c|c|c|c|c|c|c|}
\hline \multicolumn{9}{|c|}{ Fitoplankton } \\
\hline \multirow[t]{2}{*}{ No } & \multirow[t]{2}{*}{ Class } & \multirow[t]{2}{*}{ Ordo } & \multirow[t]{2}{*}{ Familia } & \multirow[t]{2}{*}{ Species } & \multicolumn{4}{|c|}{ Tata Guna Lahan (Ind/L) } \\
\hline & & & & & TKN & PMK & PBR & JLH \\
\hline 1 & Chlorophyceae & Oedogonales & Oedoniaceae & Oedogonium $\mathrm{sp}$ & 3.75 & 6.88 & 0.63 & 11.26 \\
\hline 2 & & Zygnematales & Zygnemataceae & Spirogyra varians & 4.38 & 4.38 & 0.63 & 9.39 \\
\hline 3 & & Chlorococcales & Characiaceae & Characium limneticum & 3.75 & 7.5 & 0 & 11.25 \\
\hline 4 & & & Hydrodictyaceae & Pediastrum simplex & 6.25 & 5 & 0 & 11.25 \\
\hline 5 & & Ulotrichales & Microsporaceae & Microspora $\mathrm{sp}$ & 5.62 & 5 & 0.63 & 11.25 \\
\hline 6 & & Chlorodendrales & Chlorodendraceae & Tetraselmis sp & 5 & 5.63 & 1.88 & 12.51 \\
\hline 7 & & Chlamydomonadales & Haemotococcacea & Chlorogonium $\mathrm{sp}$ & 5 & 4.38 & 1.88 & 11.26 \\
\hline 8 & Euglenophyceae & Euglenales & Euglenaceae & Euglena viridis & 3.75 & 4.38 & 1.25 & 9.38 \\
\hline 9 & & & & Trachelomonas oblonga & 2.5 & 5 & 0 & 7.5 \\
\hline 10 & & & & T.dybowski & 2.5 & 3.13 & 0 & 5.63 \\
\hline 11 & & & & T.volzii & 1.88 & 3.13 & 0 & 5.01 \\
\hline 12 & & & & T.curta & 4.38 & 1.25 & 0 & 5.63 \\
\hline 13 & & & & T.ovoides & 2.5 & 2.5 & 0 & 5 \\
\hline 14 & Bacillariophyceae & Pennales & Diatomaceae & Diatoma $\mathrm{sp}$ & 3.13 & 3.13 & 0.63 & 6.89 \\
\hline 15 & & & & Synedra ulna & 3.13 & 16.25 & 7.5 & 26.88 \\
\hline 16 & & Centrales & Cyclotellaceae & Cyclotella comta & 0.63 & 0.63 & 0 & 1.26 \\
\hline 17 & & Nostocales & Nostocaceae & Anabaena affinis & 3.75 & 4.38 & 0 & 8.13 \\
\hline 18 & & & & A. spiroides & 3.13 & 3.13 & 0 & 6.26 \\
\hline 19 & & Eunotiales & Eunotiaceae & Eunotia sp & 1.25 & 0 & 0 & 1.25 \\
\hline 20 & & Navicullales & Naviculaceae & Navicula planctonicum & 4.38 & 4.38 & 0 & 8.76 \\
\hline 21 & & & & N. substillissima & 3.75 & 3.75 & 0 & 7.5 \\
\hline \multirow[t]{2}{*}{22} & Dinophyceae & Peridiniales & Peridiniaceae & Peridinium $s p$ & 0 & 0 & 8.13 & 8.13 \\
\hline & JUMLAH & & & & 74.38 & 93,76 & 23.13 & 191.38 \\
\hline \multicolumn{9}{|c|}{ Zooplankton } \\
\hline \multirow[t]{2}{*}{ No } & Class & Ordo & Familia & Species & \multicolumn{4}{|c|}{ Tata Guna Lahan (ind/L) } \\
\hline & & & & & TKN & PMK & PBR & JLH \\
\hline 1 & Branchiopoda & Cladocera & Daphniidae & Daphnia sp & 4.38 & 1.25 & 1.25 & 6.88 \\
\hline 2 & Crustaceae & Copepoda & Opepodidae & Nauphilus sp & 1.88 & 3.13 & 1.88 & 6.89 \\
\hline 3 & Maxillopoda & Cyclopoida & Cyclopidae & Cyclops scutifer & 6.25 & 8.13 & 6.25 & 20.63 \\
\hline 4 & & Calanoida & Diaptomidae & Diaptomus $\mathrm{sp}$ & 5 & 3.75 & 1.25 & 10 \\
\hline 5 & Monogononta & Ploimida & Branchionidae & Keratella cochlearis & 3.13 & 2.5 & 0 & 5.63 \\
\hline 6 & & & & K.quadrata & 3.13 & 2.5 & 0 & 5.63 \\
\hline 7 & & & & Brachionus angularis & 1.88 & 1.88 & 0.63 & 4.39 \\
\hline 8 & & & Trichocerdidae & Trichocerca stylata & 1.25 & 0 & 1.25 & 2.5 \\
\hline Jum & & & & & 26.88 & 23.13 & 11.25 & 62.55 \\
\hline
\end{tabular}

Keterangan : (-) tidakditemukan; TKN: tangkapan nelayan; PMK : pemukiman; PBR : kawasan pabrik

Tabel 1 menunjukkan kelimpahan fitoplankton dan zooplankton secara umum tertinggi berada pada kawasan pemukiman. Sementara kelimpahan fitoplankton tertinggi dimiliki Synedra ulna di 3 kawasan tata guna lahan, dengan kelimpahan total sebesar 26,88 individu/liter. Kelimpahan terendah dimiliki Cyclotella comtadan Eunotia sp sebesar 1.25 individu/liter. Tingginya kelimpahan plankton di kawasan pemukiman diduga disebabkan karena pada stasiun ini faktor fisika lingkungan perairan cukup mendukung. Menurut Ali (2013), fitoplankton berkembang baik pada lingkungan dengan unsur hara, sinar matahari, suhu yang baik sehingga menyumbangkan nutrient yang baik untuk memproduksi materi organik melalui proses fotosintesis.

Melimpahnya Synedra ulna di ekosistem perairan menunjukkan indikasi lingkungan tersebut tercemar ringan. Kondisi tiga stasiun yang memiliki nilai BOD dan COD yang cukup tinggi diduga menjadi penyebab tingginya kelimpahan Synedra ulna.Menurut Rosarina dan Rosanti (2018), kadungan BOD dan COD yang tinggi menjadi pemicu pertumbuhan Synedra ulna yang semakin cepat.

Kelimpahan zooplankton tertinggi secara total dimiliki Cyclops scutifer dengan nilai 20,63 individu/liter. Kelimpahan total zooplankton tertinggi ditemukan pada stasiun 1. Tingginya 
kelimpahan zooplankton pada stasiun 1 diduga karena pada kawasan ini, banyak ditemukan tumbuhan dan kedai makanan, sehingga sisa-sisa bahan organik yang dibuang pada kawasan ini menyebabkan nutrien yang cukup banyak ke perairan. Sumbangan nutrien yang banyak ke wilayah perairan akan memicu tumbuhnya plankton.

Dari ketiga stasiun, zooplankton dari jenis Cyclopsscutifermemiliki kelimpahan tertinggi.Tingginya kelimpahan Cyclopsscutiferdisebabkan species ini merupakan pemakan bakteri di perairan yang banyak mengandung bahan organik. Oleh karena itu, Cyclopsscutiferditemukan di semua stasiun (Rosarina dan Rosanti, 2018).

\section{Keanekaragaman}

Keanekaragaman

dapat

menunjukkan keberadaan suatu spesies dalam suatu komunitas pada suatu ekosistem. Tingginya suatu keanekaragaman menunjukkan keberadaan suatu ekosistem yang sangat stabil dan seimbang serta mampu memberikan peranan dan fungsi yang besar dalam menjaga keseimbangan terhadap kejadian yang bisa merusak suatu ekosistem. Indeks Keanekaragaman adalah menggambarkan analisis informasi mengenai jumlah individu perliter serta seberapa banyak jenis yang ada dalam suatu komunitas (Odum, 1971). Berdasarkan analisis data didapat Indeks Keanekaragaman $\left(\mathrm{H}^{\prime}\right)$ seperti pada tabel 2 berikut ini.

Tabel 2 Indeks Keanekaragaman Plankton pada Tata Guna Lahan di Sungai Cisadane Kota Tangerang

\begin{tabular}{lllll}
\hline No & Tata Guna Lahan & \multicolumn{2}{l}{ Indeks keanekaragaman $\left(\mathrm{H}^{\prime}\right)$} & \multirow{2}{*}{ Kriteria } \\
\cline { 3 - 4 } & & Fitoplankton & Zooplankton & \\
\hline 1 & Tangkapan Nelayan & 2,65 & 1,96 & Sedang \\
2 & Perumahan & 2,82 & 1,78 & Sedang \\
3 & Kawasan Pabrik & 1,32 & 1,27 & Sedang \\
\hline
\end{tabular}

Tabel 2 menunjukkan indeks keanekaragaman plankton di tiga stasiun tergolong sedang. Nilai tersebut menunjukkan bahwa komunitas organisme dalam kondisi yang kurang beragam. Selain kurang beragam, jumlah individu per-jenisnya juga termasuk kecil. Hal ini diduga karena pencemaran dapat mengubah struktur ekosistem dan mengurangi jumlah spesies dalam suatu komunitas, sehingga keragamannya berkurang. Berbagai aktivitas di sekitar sungai menjadi salah satu penyebab pencemaran. Dengan demikian indeks diversitas ekosistem yang tercemar selalu lebih kecil dari pada ekosistem alami.

Planktonmerupakan

mikroorganisme yang hidup melayang di perairan. Mikroorganisme ini baik dari segi jumlah dan spesiesnya sangat banyak dan sangat beranekaragam serta sangat padat. Plankton juga merupakan salah satu komponen utama dalam sistem mata rantai makanan dan jaring makanan. Plankton menjadi pakan bagi sejumlah konsumen dalam sistem mata rantai makanan dan jaring makanan tersebut.

Plankton dapat dibagi menjadi 2 golongan utama, yaitu fitoplankton yang disebut plankton nabati dan zooplankton yang disebut plankton hewani (ukurannya lebih besar dari fitoplankton). Plankton baik fitoplankton maupun zooplankton memiliki peranan penting bagi perairan atau ekosistem laut, karena plankton menjadi bahan makanan bagi berbagai jenis hewan perairan lainnya. 
Dalam suatu perairan, struktur komunitas plankton dapat dijadikan sebagai indikator biologis untuk menilai tingkat pencemaran. Bervariasinya keberadaan plankton disebabkan oleh berbeda-bedanya kemampuan adaptasi masing-masing genus terhadap habitatnya (Mirna dan Makri, 2011).

Fitoplankton berperan penting dalam suatu perairan yang fungsi ekologinya sebagai produsen primer dan sering dijadikan indikator kesuburan suatu perairan (Isnaini, 2012). Fitoplankton memiliki fungsi penting sebagai produser primer di suatu perairan karena bersifat autotrof, maka dapat menghasilkan sendiri bahan organik makanannya. Fitoplankton memiliki klorofil sehingga mampu berfotosintesis, yaitu menangkap energi matahari dan mengubah bahan anorganik menjadi bahan organik (Davieset al., 2010).

$$
\text { Zooplankton merupakan }
$$

organisme akuatik yang memainkan peran yang sangat penting dalam menopang rantai makanan di laut. Walaupun daya geraknya terbatas dan distribusinya ditentukan oleh keberadaan makanannya, zooplankton berperan pada tingkat energi yang kedua yang menghubungkan produsen utama (fitoplankton) dengan konsumen dalam tingkat makanan yang lebih tinggi.Apabila kondisi lingkungan dan ketersediaan fitoplankton tidak sesuai dengan kebutuhan zooplankton maka zooplankton akan mencari kondisi lingkungan dan makanan yang lebih sesuai (Kusmeri dan Rosanti, 2015).

Sungai Cisadane telah mengalami dapak akibat perubahan tata guna lahan. Selain menjadikawasan pemukiman, taman kota, juga menjadi jalur transportasi dengan perahu kecil untuk menyebrangkan warga dari tepian yang satu ke tepian yang lain. Para nelayan juga bisa mengambil kekayaan sungai untuk mencari ikan. Semua aktivitas tersebut mempengaruhi kualitas air dan mempunyai potensi mencemari perairan di sungai Cisadane, yang berdampak pada menurunnya kualitas air. Menurut Tajangenyasha dan Dzinomwa dalam Agustiningsih et al. (2012), perubahan kondisi kualitas air sungai merupakan dampak dari buangan kegiatan industri dan pemukiman di sekitar daerah aliran sungai, yang diduga berpengaruh terhadap sturktur komunitas plankton di kawasan Sungai Cisadane.

\section{KESIMPULAN}

1. Struktur komunitas plankton di sungai Cisadane pada tata guna lahan yang berbeda terdiri dari 22 species fitoplankton dan 8 species zooplankton.

2. Kelimpahan fitoplankton tertinggi dimiliki oleh Synedra ulna dan kelimpahan zooplankton tertinggi dimilikiCyclops scutifer.

3. Keanekaragaman plankton di tiga tata guna lahan dapat dikategorikan sedang, dengan nilai indeks keanekaragaman berkisar 1,27-2,82.

\section{Ucapan Terima Kasih}

Kemenristekdikti, Universitas Muhammadiyah Tangerang dan Universitas PGRI Palembang yang telah membiayai penelitian ini.

\section{DAFTAR PUSTAKA}

Agustiningsih, D.,S.B.Sasongko dan Sudarno. (2012). Analisis Kualitas Air dan Strategi Pengendalian Pencemaran Air Sungai Blukar Kabupaten Kendal.Jurnal Presipitasi. Volume 9 No 2 September 2012. Universitas Diponegoro.Semarang.

Ali, M. (2013). Kelimpahan Plankton di Waduk Gajah Mungkur Jawa Tengah. Prosiding Forum Perairan Umum Indonesia ke-10. 
Departemen Kelautan dan Perikanan. Jakarta.

Davies, O.A.dan E. Ansa. (2010). Comparative Assessment Of Water Quality Parameters Of Freshwater Tidal Earthen Ponds And Stagnant Concerete Tanks For Fish Production In Port Harcourt, Nigeria. International Journal of Science And Nature. Vol 1 (1). 3437.

Isnaini. (2014). Struktur Komunitas Fitoplankton di Perairan Muara Sungai Banyuasin Kabupaten Banyuasin Sumatera Selatan. Maspari Journal. Vol 4(1). Fakultas MIPA Universitas Sriwijaya. Palembang.

Kusmeri, L., \& Rosanti, D. (2015). Struktur Komunitas Zooplankton di Danau Opi Jakabaring Palembang. Sainmatika: Jurnal Ilmiah Matematika dan Ilmu Pengetahuan Alam, 12(1).

Mirna dan Makri. (2011). Kelimpahan dan Komunitas Zooplankton di Sungai Siak Indrapura Bagian Hilir Danau. Prosiding Forum Perairan Umum Indonesia ke-8. Kementrian Kelautan dan Perikanan. Jakarta

Mizuno, T. (1979). Ilustrations of the Freshwater Plankton of Japan. Hoikusha Publishing. Higashi Osaka. Japan.

Odum. E., P. (1971). Fundamental of Ecology. Thrird Ed. W.B.Saunders Co. USA.

Rosarina, D., \& Laksanawati, E. K. (2018). Studi Kualitas Air Sungai Cisadane Kota Tangerang Ditinjau dari Parameter Fisika. Jurnal Redoks, 3(2), 38-43.

Rosarina, D. dan E.K. Laksanawati. (2018.b). Studi Kualitas Air Sungai Cisadane Kota Tangerang Ditinjau dari Sifat Kimia. Prosiding Prosiding Semnas SINTA FT UNILA Vol. 1 Tahun 2018 Riset
PT-Eksplorasi Hulu Demi Hilirisasi Produk. Bandar Lampung.

Rosarina, Desy, and Ellysa Kusuma Laksanawati."Studi Kualitas Air Sungai Cisadane Kota Tangerang Ditinjau dari Sifat Kimia."

Rosarina, D., \& Rosanti, D. (2018, October).Struktur Komunitas Plankton di Sungai Cisadane Kota Tangerang.In Prosiding Seminar Nasional Sains dan Teknologi (Vol. 1, No. 1).

Wahyuni, I. S., \& Rosanti, D. (2016). Keanekaragaman Fitoplankton Di Kolam Retensi Kambang Iwak Kota Palembang.Sainmatika: Jurnal Ilmiah Matematika dan Ilmu Pengetahuan Alam, 13(2). 